\title{
KEADAAN SOSIAL EKONOMI MASYARAKAT PEMBUDIDAYA IKAN MAS (Cyprinus carpio L) DI DESA TATELU KECAMATAN DIMEMBE KABUPATEN MINAHASA UTARA
}

\author{
Timmy Wulur ${ }^{1}$; Jeannette F. Pangemanan'; Grace 0. Tambani² \\ 1)Mahasiswa Fakultas Perikanan dan IImu Kelautan Universitas Sam Ratulangi Manado \\ 2)Staff Pengajar Fakultas Perikanan dan IImu Kelautan Universitas Sam Ratulangi Manado \\ Koresponden email: timmywulur96@gmail.com
}

\begin{abstract}
This study aims to reveal and examine the socio-economic conditions of carp farmers in Tatelu Village, Dimembe District, North Minahasa Regency. The method used in this study is descriptive. Data was collected from carp fish communities in Tatelu Village, Dimembe District using direct questions and interviews, filling out questionnaires and recording devices. The results of the study of the social conditions of carp farmers in Tatelu Village include nearly $50 \%$ of farmers who have high school education and they can adopt technologies introduced for farmers. The economic situation of carp farmers in Tatelu Village consists of working capital with a source of own capital, only two farmers use loan capital from the Bank. The results of goldfish cultivation in Tatelu Village are marketed to collector traders (fish depots), then these traders sell it to consumers who are sold in retail. The selling price of carp is IDR $40,000 / \mathrm{Kg}$ and the retail price is IDR 50,000 - IDR 60,000/ $\mathrm{Kg}$. The average total income of farmers is Rp. $18,512,000$ / month with an average expenditure per month of Rp. 6,020,000, -
\end{abstract}

Key Words: Goldfish, social aspects, economic aspects, Tatelu Village

\begin{abstract}
Abstrak
Penelitian ini bertujuan untuk mengungkapkan dan mengkaji keadaan sosial ekonomi pembudidaya ikan mas di Desa Tatelu Kecamatan Dimembe Kabupaten Minahasa Utara. Metode yang digunakan dalam penelitian ini bersifat deskriptif. Data dikumpulkan dari masyarakat pembudidaya ikan mas yang ada di Desa Tatelu Kecamatan Dimembe menggunakan pertanyaan-pertanyaan dan wawancara langsung, pengisian kuisoner dan juga alat perekam. Hasil penelitian keadaan sosial pembudidaya ikan mas di Desa Tatelu antara lain hampir 50\% pembudidaya sudah berpendidikan Sekolah Lanjutan Atas (SLTA) dan mereka dapat mengadopsi teknologi yang diperkenalkan bagi pembudidaya. Keadaan ekonomi pembudidaya ikan mas di Desa Tatelu terdiri dari modal kerja dengan sumber modal sendiri, hanya dua pembudidaya yang menggunakan modal pinjaman dari Bank. Hasil usaha budidaya ikan mas di Desa Tatelu dipasarkan kepada pedagang pengumpul (depot ikan) selanjutnya pedagang pengumpul ini memasarkannya ke konsumen yang dijual secara eceran. Harga jual ikan mas Rp 40.000/Kg dan harga eceran Rp 50.000 - Rp 60.000/Kg. Total pendapatan rata-rata pembudidaya Rp 18.512.000/bulan dengan rata-rata pengeluaran per bulannya Rp. 6.020 .000
\end{abstract}

Kata Kunci: Pembudidaya, Ikan Mas, aspek sosial, aspek ekonomi, Desa Tatelu

\section{PENDAHULUAN}

Pembangunan perikanan bukan hanya persoalan peningkatan pendapatan, tetapi untuk meningkatkan taraf hidup dan kesejahteraan nelayan dan petani ikan serta memperbaiki status sosial dan ekonomi dari keluarganya, sejalan dengan pembangunan itu maka tidak lepas dari pedoman pembangunan daerah yang dalam pelaksanaannya disesuaikan dengan petani dan pioritas yang ada di daerah tersebut.

Keadaan sosial ekonomi merupakan kedudukan atau posisi seorang dalam kelompok manusia yang ditentukan oleh jenis aktivitas ekonomi, pendapatan, tingkat pendidikan, usia, jenis rumah tinggal dan kekayaan yang dimiliki (Abdulsyani, 1994). Sebagian besar kategori sosial pembudidaya Indonesia adalah pembudidaya tradisional, mereka adalah penyumbang utama kuantitas produksi perikanan tangkap nasional.

Desa Tatelu adalah salah satu desa yang terletak di Kecamatan Dimembe yang memiliki pembudidaya ikan sebagai sumberdaya manusia dalam hal ini melakukan kegiatan usaha budidaya ikan dikolam,dimana kegiatan budidaya di desa ini telah berlangsung lama tetapi data atau informasi tentang kehidupan sosial ekonomi dari pembudidaya ikan, belum banyak 
terungkap baik dari laporan-laporan maupun dari tulisan-tulisan ilmiah.

\section{METODE PENELITIAN}

Penelitian ini menggunakan jenis penelitian yang bersifat deskriptif dengan dasar penelitian adalah studi kasus, dengan mengambil kasus pada pembudidaya ikan mas di kolam, sebagai sarana pemeliharaan ikan. Studi kasus yaitu penelitian yang dilakukan dengan cara mempelajari suatu kasus tertentu pada objek yang terbatas (Mantjoro, 1987). Penelitian bersifat deskriptif adalah penelitian yang bertujuan untuk mengungkapkan suatu kenyataan sosial dengan jalan mendeskripsikan secara tepat sifat-sifat individu, keadaan, gejala, kelompok tertentu berkenaan dengan masalah unit yang diteliti dalam masyarakat (Faisal, 2003).

Penelitian ini menggunakan metode sensus. Metode sensus adalah teknik penentuan sampel bila semua anggota populasi digunakan menjadi sampel (Sugiyono, 2002). Yang menjadi populasi adalah pembudidaya ikan mas yang ada di Desa Tatelu sebanyak 10 orang.

Pengumpulan data dilakukan
secara observasi dengan melihat keseluruhan dari masyarakat pembudidaya ikan mas yang ada di Desa Tatelu Kecamatan Dimembe karena yang menjadi populasi adalah seluruh petani ikan mas yang ada di Desa Tatelu.

Analisis data hasil penelitian dibedakan dalam dua macam, yaitu analisis kuantitatif dan analisis kualitatif (Fathoni, 2006). Analisis kuantitatif merupakan pengolahan data dengan menggunakan perhitungan matematis sederhana seperti penjumlahan, pengurangan, perkalian, angka rata-rata, persentase (\%) dan sebagainya, yang meliputi analisis usaha aspek keuangan, sumberdaya manusia, operasi/produksi dan pemasaran. Sedangkan analisis kualitatif adalah pengolahan data yang dilakukan melalui pertimbanganpertimbangan logika dengan bahasa penulis yang sistematis. Data yang telah dianalisis kemudian diinterpretasikan sebagai hasil penelitian, yang meliputi wawancara, analisis dokumen, diskusi, atau observasi pertimbanganpertimbangan logika dengan bahasabahasa penulis yang sistematis.

\section{HASIL DAN PEMBAHASAN \\ Keadaan Sosial \\ Tingkat Pendidikan}

Tingkat pendidikan merupakan salah satu aspek sosial yang penting bagi pembudidaya, karena berpengaruh terhadap adopsi teknologi, karena apabila hanya mempunyai tingkat pendidikan yang rendah akan sulit untuk menerima teknologi yang baru. Pendidikan juga merupakan salah satu faktor utama yang dapat membuka kesempatan kerja bagi pembudidaya yang hidupnya hanya paspasan saja. Hasil penelitian terhadap tingkat pendidikan dari pembudidaya ikan mas di Desa Tatelu dapat dilihat pada Tabel 1 berikut ini.

Tabel 1. Keadaan Sosial Berdasarkan Pendidikan

\begin{tabular}{|c|c|c|c|}
\hline No. & $\begin{array}{c}\text { Tingkat } \\
\text { Pendidikan }\end{array}$ & $\begin{array}{c}\text { Jumlah } \\
\text { (jiwa) }\end{array}$ & $\begin{array}{c}\text { Persentase } \\
(\%)\end{array}$ \\
\hline 1. & SLTP & 6 & 60 \\
\hline 2. & SLTA & 4 & 40 \\
\hline & Jumlah & 10 & 100 \\
\hline
\end{tabular}

Sumber: Data Primer, 2019

Tabel menunjukkan bahwa tingkat pendidikan pembudidaya ikan mas paling dominan adalah SMP yaitu $40 \%$ saja. Hal ini menggambarkan bahwa pendidikan pembudidaya ikan mas di Desa Tatelu sudah baik sebab hampir 50\% pembudidaya sudah berpendidikan sekolah menengah pertama dan hal ini sangat di perlukan bagi mereka agar cepat mengadopsi teknologi yang baru 
apabila sewaktu-waktu diperkenalkan bagi pembudidaya untuk dilaksanakan. Mereka tidak buta huruf lagi bahkan sudah memiliki pendidikan yang lebih lanjut dari sekolah lanjutan pertama.

\section{Pengalaman Kerja}

Pengalaman kerja merupakan hal yang penting dalam proses pembudidayaan ikan mas, karena hal ini dapat membentuk keterampilan serta keahlian dalam menangani permasalahan di lapangan. Misalnya cara membudidaya ikan mas yang baik dan benar, agar tidak gagal panen sehingga mengalami kerugian. Pengalaman kerja pembudidaya ikan mas dapat dilihat pada Tabel 2 berikut ini.

Tabel 2. Keadaan Sosial Berdasarkan Pengalaman Kerja

\begin{tabular}{|c|c|c|c|}
\hline No & Pengalaman Kerja & $\begin{array}{c}\text { Jumlah } \\
\text { Pembudidaya } \\
\text { Ikan }\end{array}$ & $\begin{array}{c}\text { Persentase } \\
(\%)\end{array}$ \\
\hline 1. & $7-10$ tahun & 2 & 20 \\
\hline 2. & $11-15$ tahun & 3 & 30 \\
\hline 3. & $16-20$ tahun & 5 & 50 \\
\hline \multicolumn{2}{|c|}{ Total } & 10 & 100 \\
\hline
\end{tabular}

Sumber: Data Primer, 2019

Hasil penelitian menunjukkan bahwa pengalaman kerja pembudidaya ikan mas di desa Tatelu bervariasi karena dari 10 orang pembudidaya ikan mas ada yang $20 \%$ berpengalaman 7 tahun sampai 10 tahun melakukan kegiatan ini, dan ada 30\% yang berpengalaman 11 tahun sampai 15 tahun. Data yang di peroleh dari hasil penelitian ternyata dari 10 orang pembudidaya ikan ada 5 orang atau $50 \%$ yang sudah melakukan pekerjaan ini sekitar 16 tahun sampai 20 tahun lamanya. Hal seperti ini menggambarkan bahwa pengalaman mereka dapat melakukan kegiatan ini sudah lama itu berarti bahwa pembudidaya ikan mas di desa ini sudah mengetahui banyak tentang seluk beluk maupun permasalahan-permasalahan yang terjadi dalam cara membudidayakan ikan mas.

\section{Agama dan Suku}

Pembudidaya ikan mas dalam penelitian ini semuanya beragama Kristen Protestan, dan semuanya berasal dari Suku Minahasa.

\section{Keadaan Rumah Tempat Tinggal}

Pembudidaya ikan mas yang di Desa Tatelu paling banyak terdapat pada jaga 4 disebabkan karena jaga tersebut merupakan tempat yang paling strategis untuk membudidaya ikan dan dekat dengan sumber air. Berikut ini adalah jenis rumah pembudidaya ikan mas yang ada di Desa Tatelu yang dijelaskan pada Tabel 3.

Tabel 3. Keadaan Sosial Berdasarkan Rumah Tempat Tinggal

\begin{tabular}{|c|c|c|c|}
\hline No. & $\begin{array}{c}\text { Jenis Tempat } \\
\text { Tinggal }\end{array}$ & $\begin{array}{c}\text { Jumlah } \\
\text { (jiwa) }\end{array}$ & $\begin{array}{c}\text { Persentase } \\
(\%)\end{array}$ \\
\hline 1. & Permanen & 5 & 50 \\
\hline 2. & Semi Permanen & 5 & 50 \\
\hline & Jumlah & 10 & 100 \\
\hline
\end{tabular}

Sumber: Data Primer, 2019

Dari Tabel di atas dapat dilihat bahwa perumahan pembudidaya ikan di Desa Tatelu paling tinggi adalah perumahan jenis permanen dengan jumlah 5 rumah atau $50 \%$. Perumahan jenis semi permanen hanya berjumlah 3 rumah $(30 \%)$ dan ada yang jenis perumahan non permanen yaitu 2 rumah $(20 \%)$ saja. Hal ini menggambarkan bahwa untuk rumah tinggal dari pembudidaya ikan mas sudah baik atau lebih layak untuk ditempati bersama terdiri dari dari jenis rumah permanen dan seni permanen. Kondisi lingkungan terutama di sekitar rumah tempat tinggal kurang bersih hal ini dapat dilihat di sana sini terdapat sampah yang berserahkan terutama sampah-sampah minuman yang terbuat dari bahan plastik sesudah dikonsumsi masyarakat hanya membuang sampah di halaman rumah. 
Hal ini selain menggangu kesehatan juga merusak pemandangan di sekitar rumah.

Kebutuhan pokok akan air bersih tercukupi dengan adanya mata air tawar yang digali menjadi sumur dan juga adanya pipah air yang disalurkan ke rumah-rumah penduduk.

\section{Umur}

Umur merupakan salah satu faktor yang dapat memberikan gambaran tentang cara pandang seseorang. Terkadang semakin dewasa umur seseorang semakin bijak ia menyikapi atau merespon sesuatu. Berdasarkan umur pendudukyang berusia 0-14 tahun merupakan penduduk yang belum produktif, penduduk yang berusia 15-64 tahun merupakan penduduk dengan usia produktif, sedangkan penduduk yang berusia 65 tahun ke atas merupakan penduduk dengan usia kurang produktif (Kusumowidho, 2000). Hasil penelitian terhadap umur responden pembudidaya ikan mas dapat dilihat pada Tabel 4 berikut.

Tabel 4. Keadaan Sosial Berdasarkan Umur

\begin{tabular}{|c|c|c|c|}
\hline No. & $\begin{array}{c}\text { Umur } \\
\text { (tahun) }\end{array}$ & $\begin{array}{c}\text { Jumlah } \\
\text { (jiwa) }\end{array}$ & $\begin{array}{c}\text { Persentase } \\
(\%)\end{array}$ \\
\hline 1. & $35-40$ & 3 & 30 \\
\hline 2. & $41-52$ & 5 & 50 \\
\hline 3. & $53-62$ & 2 & 20 \\
\hline & Jumlah & 10 & 100 \\
\hline
\end{tabular}

Sumber: Data Sekunder, 2019

Tabel di atas menunjukkan bahwa persentase dari umur pembudidaya adalah antara umur 41-52 tahun dengan jumlah 5 orang (50\%), merupakan yang usia produktif dan dalam kondisi tubuh yang paling baik untuk melakukan aktivitas sehari-hari.

\section{Tanggungan Keluarga}

Salah satu faktor yang penting mengenai keadaan sosial pembudidaya adalah ukuran keluarga, hal ini disebabkan karena semakin banyak jumlah anggota keluarga maka jumlah kebutuhan semakin banyak. Jumlah tanggungan keluarga pembudidaya ikan mas dapat dilihat pada Tabel 5 berikut ini.

Tabel 5. Keadaan Sosial Berdasarkan Tanggungan Keluarga

\begin{tabular}{|c|c|c|c|}
\hline No. & $\begin{array}{c}\text { Jumlah } \\
\text { Tanggungan }\end{array}$ & $\begin{array}{c}\text { Jumlah Kepala } \\
\text { Keluarga (KK) }\end{array}$ & $\begin{array}{c}\text { Persentase } \\
(\%)\end{array}$ \\
\hline 1. & 5 orang & 5 & 50 \\
\hline 2. & 4 orang & 4 & 40 \\
\hline 3. & 3 orang & 1 & 10 \\
\hline \multicolumn{2}{c|}{ Total } & 10 & 100 \\
\hline
\end{tabular}

Sumber: Hasil Penelitian, 2019

Tabel 5 menunjukkan bahwa jumlah tanggungan keluarga yang paling sedikit berjumlah 3 yang terdiri dari bapak, ibu, dan anak, sedangkan jumlah tanggungan keluarga yang terbanyak ialah 5 orang Semakin sedikit tanggungan keluarga maka jumlah kebutuhan dalam suatu keluarga akan semakin sedikit pengeluaran sehingga memberikan peluang untuk menabung.

Banyaknya jumlah anggota keluarga 3 - 5 orang akan mempengaruhi tinggi rendahnya dan besarnya konsumsi keluarga. Oleh karena itu, jumlah anggota keluarga atau besar keluarga akan memberi dorongan bagi rumah tangga bersangkutan untuk lebih banyak menggali sumber pendapatan lainnya. Dengan demikian, kemampuan melihat ke depan dengan mengadakan perncanaan biaya dipengaruhi oleh tingkat sosial ekonomi penduduk dan semakin bayak anggota rumah tangga cenderung semakin sulit merencanakan biaya (Surroyo, 2017).

Besarnya beban tanggungan keluarga pada setiap pembudidaya ikan mas, responden yang berjumlah 10 orang akan berpengaruh terhadap tingkat kebutuhan dan kesejahteraan mereka; semakin banyak tanggungan keluarga maka semakin banyak pula kebutuhan rumah tangga yang harus dipenuhi. Dan jika pendapatan dari pembudidaya tidak mampu mencukupi kebutuhan sehari-hari 
maka hal ini akan berdampak pada masalah kesejahteraan dalam keluarga

\section{Keadaan Ekonomi Modal Kerja}

Modal merupakan salah satu faktor yang sangat diperlukan untuk mengembangkan usaha. Modal kerja yang dibutuhkan usaha budidaya ikan mas ini antara lain biaya pembelian benih, makanan ikan berupa pelet, dan biaya tenaga kerja. Adapun sumber modal yang digunakan oleh pembudidaya ikan mas dapat dilihat pada Tabel 6.

Tabel 6. Sumber Modal Pembudidaya Ikan Mas

\begin{tabular}{|c|l|c|c|}
\hline No. Nama & \multicolumn{1}{|c|}{$\begin{array}{c}\text { Jumlah Modal } \\
(\text { Rp })\end{array}$} & Sumber Modal \\
\hline 1. & Nicolas Tidayoh & 10.000 .000 & Modal Sendiri \\
\hline 2. & Jeksen Timbuleng & 10.000 .000 & Modal Sendiri \\
\hline 3. & Okman Sahapudi & 15.000 .000 & Bank \\
\hline 4. & Silvana Ticoalu & 7.000 .000 & Modal Sendiri \\
\hline 5. & Fanda Rumagit & 10.000 .000 & Modal Sendiri \\
\hline 6. & Jhony Nusah & 10.000 .000 & Modal Sendiri \\
\hline 7. & Emma Piri & 12.000 .000 & Modal Sendiri \\
\hline 8. & Agnes Panawar & 10.000 .000 & Bank \\
\hline 9. & Femmy wullur & 10.000 .000 & Modal Sendiri \\
\hline 10. & Decky Ticoalu & 7.000 .000 & Modal Sendiri \\
\hline
\end{tabular}

Sumber: Hasil Penelitian Tahun, 2019

Tabel 6 menunjukkan bahwa ada dua responden yang memiliki modal pinjaman yang berasal dari bank, sedangkan respoden yang menggunakkan modal sendiri lebih banyak dari modal pinjaman yang berasal bank. Hal ini disebabkan karena perbedaan pendapat antara pinjaman modal dari bank dengan modal sendiri, salah satu responden yang menjelaskan tentang pijaman di bank bukan karena tidak memiliki uang/modal usaha tetapi menurutnya pinjaman di bank lebih menguntungkan dibandingkan dengan modal sendiri. Karena modal sendiri dapat digunakan untuk kebutuhan seharihari dan bisa ditabung di bank, dan untuk pembayaran angsuran di bank dapat diambil dari hasil usaha tersebut. Sedangkan untuk modal sendiri mereka lebih cenderung berprinsip tidak mau berhutang.

\section{Pendapatan}

Harga ikan yang dipasarkan ditentukan oleh pembeli dan penjual, terkadang harga ikan yang dipasarkan bervariasi harganya artinya tidak tetap tergantung dari mutu ikan. Harga ikan mas perkilogramnya $\mathrm{Rp} 40.000$ beli langsung ke petani ikan pembudidaya ikan mas, dan harga di konsumen Rp. 50.000 - Rp. 60.000 per kilogram.

Pendapatan pembudidaya ikan di Desa Tatelu dapat dilihat pada Tabel 7 . 
Tabel 7. Tingkat Pendapatan Pokok per tahun Pembudidaya Ikan Mas

\begin{tabular}{|c|c|c|c|c|}
\hline No. & Nama & $\begin{array}{l}\text { Jumlah Produksi } \\
(\mathrm{Kg})\end{array}$ & $\begin{array}{l}\text { Harga / Kg } \\
\text { (Rp) }\end{array}$ & $\begin{array}{c}\text { Jumlah } \\
\text { (Rp) }\end{array}$ \\
\hline 1 & Nicolas Tidayoh & 500 & 40.000 & 20.000 .000 \\
\hline 2 & Jeksen Timbuleng & 300 & 40.000 & 12.000 .000 \\
\hline 3 & Okman Sahapudi & 600 & 40.000 & 24.000 .000 \\
\hline 4 & Silvana Ticoalu & 500 & 40.000 & 20.000 .000 \\
\hline 5 & Fanda Rumagit & 700 & 40.000 & 28.000 .000 \\
\hline 6 & Jhony Nusah & 200 & 40.000 & 8.000 .000 \\
\hline 7 & Emma Piri & 400 & 40.000 & 16.000 .000 \\
\hline 8 & Agnes Panawar & 100 & 40.000 & 4.000 .000 \\
\hline 9 & Femmy wullur & 700 & 40.000 & 28.000 .000 \\
\hline 10 & Decky Ticoalu & 600 & 40.000 & 24.000 .000 \\
\hline & Rata-rata & 460 & 40.000 & $18.400,000$ \\
\hline
\end{tabular}

Sumber: Data Primer, 2019

Tabel 7 menunjukan bahwa pembudidaya yang berada di Desa Tatelu pendapatannya bervariasi. Jumlah produksi yang paling banyak adalah 700 $\mathrm{kg}$ dengan harga Rp 28.000.000-, dan jumlah produksi yang paling sedikit adalah $100 \mathrm{~kg}$ dengan harga Rp. 4.000.000. Jumlah produksi rata-rata sebesar $460 \mathrm{~kg}$ dengan pendapatan atau harga jual rata-rata sebesar Rp 18.400.000.

\section{Pendapatan Sampingan}

Pendapatan sampingan pembudidaya ikan dapat dilihat pada Tabel 8.

Tabel 8. Tingkat Pendapatan Sampingan per hari Pembudidaya Ikan Mas

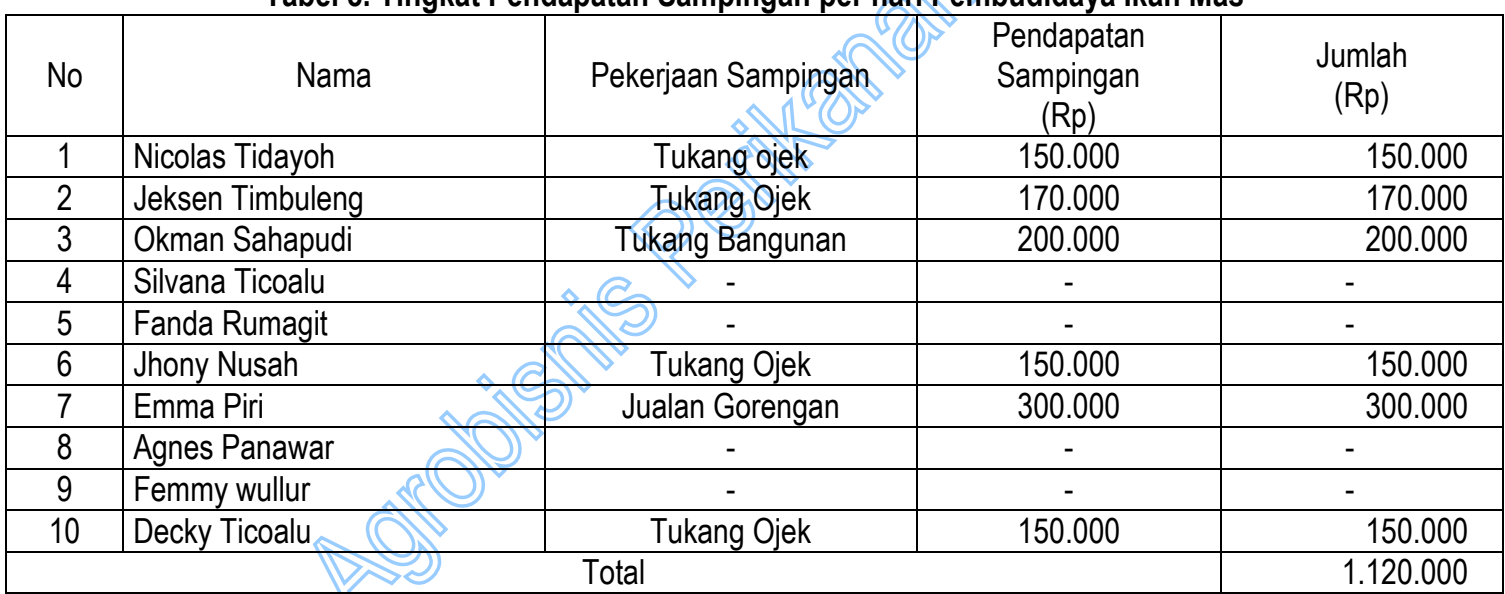

Sumber: Data Primer, 2019

Berdasarkan penelitian pendapatan sampingan pembudidaya ikan mas paling banyak adalah tukang ojek. Dari 10 responden yang diambil 4 diantaranya tidak memiliki pekerjaan sampingan sedangkan untuk tukang ojek sebanyak 4 orang, jualan gorengan 1 orang dan tukang bangunan 1 orang. Untuk pekerjaan sampingan, pendapatn paling besar adalah penjual gorengan karena mencapai Rp300.000 per hari, sedangkan untuk tukang ojek hanya Rp 150.000 - Rp170.000 per hari dan tukang bangunan $\mathrm{Rp} 200.000$ per hari. Total pendapatan pembudidaya ikan di Desa Tatelu dapat dilihat pada Tabel 9. 
Tabel 9. Jumlah Pendapatan Total Pembudidaya Ikan Mas di Desa Tatelu

\begin{tabular}{|c|l|r|r|r|}
\hline No & Nama Responden & $\begin{array}{c}\text { Pendapatan Pokok } \\
(\mathrm{Rp})\end{array}$ & $\begin{array}{c}\text { Pendapatan } \\
\text { Sampingan } \\
(\mathrm{Rp})\end{array}$ & $\begin{array}{c}\text { Jumlah } \\
(\mathrm{Rp})\end{array}$ \\
\hline 1 & Nicolas Tidayoh & 20.000 .000 & 150.000 & 20.150 .000 \\
\hline 2 & Jeksen Timbuleng & 12.000 .000 & 170.000 & 12.170 .000 \\
\hline 3 & Okman Sahapudi & 24.000 .000 & 200.000 & 24.200 .000 \\
\hline 4 & Silvana Ticoalu & 20.000 .000 & - & 20.000 .000 \\
\hline 5 & Fanda Rumagit & 28.000 .000 & - & 8.150 .000 \\
\hline 6 & Jhony Nusah & 8.000 .000 & 150.000 & 16.300 .000 \\
\hline 7 & Emma Piri & 16.000 .000 & 300.000 & 4.000 .000 \\
\hline 8 & Agnes Panawar & 4.000 .000 & - & 28.000 .000 \\
\hline 9 & Femmy wullur & 28.000 .000 & - & 24.150 .000 \\
\hline 10 & Decky Ticoalu & 24.000 .000 & 150.000 & 18.512 .000 \\
\hline & Rata-rata & 18.400 .000 & 112.000 & \\
\hline
\end{tabular}

Sumber: Data Primer, 2019

Tabel di atas menunjukkan bahwa pendapatan total responden atau pembudidyaya ikan di Desa Tatelu yang paling besar berjumlah Rp 28.000.000 sedangkan yang paling kecil berjumlah Rp 4.000.000. Secara rata-rata didapat bahwa jumlah pendapatan total responden atau pembudidaya ikan mas berjumlah Rp 18.512.000.

\section{Pengeluaran}

Biaya kebutuhan sehari-hari setiap keluarga pembudidaya ikan mas termasuk makanan, pakaian, pendidikan, kesehatan dan lainnya, disesuaikan dengan jumlah anggota keluarga, karena kemampuan suatu rumah tangga untuk membeli bahan makanan dipengaruhi oleh pendapatan yang dibatasi dengan jumlah anggota keluarga, semakin besar jumlah keluarga maka semakin tinggi, demikian juga sebaliknya. Pengeluaran pembudidaya ikan mas dalam satu bulan dapat dilihat pada Tabel 10 berikut ini.

Tabel 10. Tingkat Pengeluaran Pembudidaya Ikan Mas per Bulan

\begin{tabular}{|r|l|r|r|r|r|r|r|}
\hline No & \multicolumn{1}{|c|}{ Nama } & $\begin{array}{r}\text { Makanan } \\
(\mathrm{Rp})\end{array}$ & $\begin{array}{c}\text { Pendidikan } \\
(\mathrm{Rp})\end{array}$ & $\begin{array}{c}\text { Pakaian } \\
(\mathrm{Rp})\end{array}$ & $\begin{array}{c}\text { Kesehatan } \\
(\mathrm{Rp})\end{array}$ & Lain-lain (Rp) & $\begin{array}{c}\text { Jumlah } \\
(\mathrm{Rp})\end{array}$ \\
\hline 1 & Nicolas Tidayoh & 500.000 & 300.000 & 100.000 & 50.000 & 4.000 .000 & 4.950 .000 \\
\hline 2 & Jeksen Timbuleng & 1.000 .000 & 300.000 & 150.000 & 50.000 & 3.500 .000 & 5.000 .000 \\
\hline 3 & Okman Sahapudi & 700.000 & 600.000 & 100.000 & 150.000 & 4.000 .000 & 5.500 .000 \\
\hline 4 & Silvana Ticoalu & 750.000 & 700.000 & 100.000 & 100.000 & 4.500 .000 & 6.150 .000 \\
\hline 5 & Fanda Rumagit & 1.000 .000 & 600.000 & 100.000 & 100.000 & 5.000 .000 & 6.800 .000 \\
\hline 6 & Jhony Nusah & 750.000 & 2.000 .000 & 200.000 & 100.000 & 6.000 .000 & 9.050 .000 \\
\hline 7 & Emma Piri & 500.000 & 500.000 & 150.000 & 50.000 & 3.500 .000 & 4.700 .000 \\
\hline 8 & Agnes Panawar & 1.000 .000 & 1.000 .000 & 150.000 & 100.000 & 3.500 .000 & 5.700 .000 \\
\hline 9 & Femmy wullur & 1.000 .000 & 500.000 & 100.000 & 50.000 & 4.500 .000 & 6.150 .000 \\
\hline 10 & Decky Ticoalu & 500.000 & 1.000 .000 & 150.000 & 50.000 & 4.500 .000 & 6.200 .000 \\
\hline & Rata-rata & 770.000 & 750.000 & 130.000 & 80.000 & 4.300 .000 & 6.020 .000 \\
\hline
\end{tabular}

Sumber: Hasil Penelitian Tahun, 2019

Tingkat pengeluaran pembudidaya ikan mas di Desa Tatelu rata-rata adalah Rp $\quad 6.020 .000$ per bulan. Jenis pengeluaran yang paling besar adalah lain-lain yakni $\mathrm{Rp} \quad 4.300 .000$ per bulannyan pengeluaran lain-lain seperti biaya listrik, perlengkapan rumah tangga dan sebagainya. Jenis pengeluaran yang paling sedikit adalah kesehatan yakni $\mathrm{Rp}$ 80.000. Hal ini dikarenakan pembudidaya ikan mas dan para anggota keluarganya hampir tidak pernah diserang penyakit, karena kebiasaan masyarakat pembudidaya ikan mas untuk hidup sehat. 


\section{KESIMPULAN}

Berdasarkan hasil dan pembahasan diatas maka kondisi sosial dan ekonomi pembudidaya ikan mas dapat disimpulkan sebagai berikut:

1. Tingkat pendidikan pembudidaya ikan di Desa Tatelu adalah SLTP dan SLTA.

2. Pengalaman atau lamanya menjadi pembudidaya berkisar antara $7-20$ tahun.

3. Sebagian (50\%) pembudidaya memiliki rumah tempat tinggal jenis permanen.

4. Modal yang digunakan oleh pembudidaya ikan mas adalah modal sendiri dan modal dari bank.

5. Harga jual ikan mas Rp. 40.000/Kg pada pembudidaya ikan dan pada tingkat pengecar Rp. 50.000 - Rp. $60.000 / \mathrm{Kg}$

6. Rata-rata pendapatan dari hasil budidaya ikan mas Rp. 18.400.000 per tahun dengan jumlah harga produksi Rp. 28.000.000.

7. Rata-rata pengeluara pembudidaya yaitu; makanan Rp. 770.000, pendidikan Rp. 750.000 , pakaian Rp. 130.000, kesehatan Rp. 80.000 dan lainnya Rp. 4.300.000.

\section{DAFTAR PUSTAKA}

Cahyono, B. 2001. Budidaya lkan di Perairan Umum. Penerbit Kanisius, Yogyakarta. 95 hal.
Cholik, F., R.P. Poenomo dan A. Jauzi. 2005. Aquakultur: Tumpaan Harapan Masa Depan Bangsa Masyarakat Perikanan Nusantara dan Taman Akuarium Air Tawar. TMII, Jakarta.

Dahlan Siamat. 2001. Manajemen Lembaga Keuangan. Edisi Ketiga, Fakultas Ekonomi Indonesia, Jakarta.

Faisal, S. 2003. Dasar-Dasar Manajemen Keuangan. Edisi Pertama. Malang: Universitas Muhammadiyah.

Fathoni, A. 2006. Metodologi Penelitian dan Teknik Penyusunan Skripsi. Jakarta: PT. Rineka Cipta.

Hasibuan, Malayu, S.P. 1987. Ekonomi Pembangunan dan Perekonomian Indonesia. Bandung: Armico.

Kartono, Kartini. 2001. Pathologi Sosial 1. Bandung, Alumni.

Koentjaraningrat. 1981. Pengantar Antropologi. Jakarta: Rineka Cipta.

Kotler, Philip. 2001. Manajemen Pemasaran: Analisis, Perencanaan, Implementasi dan Kontrol. Jakarta. PT. Prehallindo.

Kotler, Philip. 2002. Manajemen Pemasaran. Edisi Milenium. Jakarta. Prehallindo.

Kusnadi. 2004. Mengatasi Kemiskinan Nelayan Jawa Timur; Pendekatan Terintegrasi, Bagaimana Harus Memulai?. dalam Kusnadi (Penyunting), Polemik Kemiskinan Nelayan, Yogyakarta: Pembaharuan.

Samuelson dan Nordhaus, 2003. IImu Makroekonomi. McGraw-Hill. Media Global Edukasi.

Santoso, B. 1993. Petunjuk Praktis Budidaya Ikan Mas. Kanisius. Yogyakarta. 77p.

Susanto. 2007. Pembangunan KTSP dalam Perspektif Manajemen Visi. (Jakarta: Matapena). 